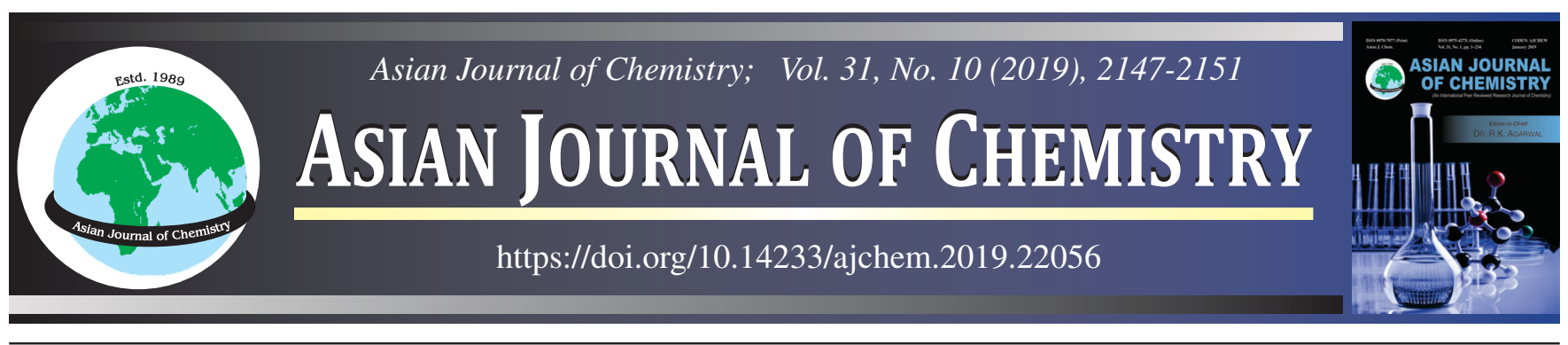

\title{
Antioxidant Activity and Phytochemical Content of Clerodendrum serratum L. from Different Provinces of Chhattisgarh State, India
}

\author{
SeEma Upadhyay ${ }^{*}$ and Vijaya Koche
}

School of Life Sciences, Pt. Ravishankar Shukla University, Raipur-492010, India

*Corresponding author: E-mail: seema2610@gmail.com

Received: 8 March 2019; Accepted: 12 April 2019; Published online: 30 August 2019;

\begin{abstract}
Clerodendrum serratum L. is one of the important medicinal plant found in Chhattisgarh state of India. Its over-exploitation for medicinal value made it a threatened species according to Chhattisgarh Medicinal Plant Board. It is being used in Ayurveda from ancient times for many diseases like asthma, body ache, bronchitis, cholera, dropsy, eye diseases, fever, inflammations, malaria, ophthalmia, rheumatism, snakebite, tuberculosis, ulcers and wounds. Present study aimed to compare the phytochemical contents and antioxidant activity of a medicinally important plant $C$. serratum L. collected from different provinces of Chhattisgarh state (India). Plants were collected from three districts of Chhattisgarh (Jagdalpur, Bilaspur and Raipur). Aerial and underground parts were separated and subjected for extraction by using different solvents of different polarity. These extracts were evaluated for phytochemical profiling, phytochemical content (total phenolic and flavonoids content) and antioxidant activity. Methanolic extract shows highest antioxidant activity and phenolic and flavonoids content among all the extracts. When the plants of different regions were compared, it was found that plants of Jagdalpur district is a potent source of phytochemical and showing highest antioxidant activity. Further, the correlation study showed that phenolics and flavonoids mainly account for antioxidant activity. It may be possible that some different groups of phytochemical act synergistically together with the phenolics and flavonoids and provide antioxidant effect.
\end{abstract}

Keywords: Clerodendrum serratum L., Phenolics, Flavonoids, Antioxidant activity.

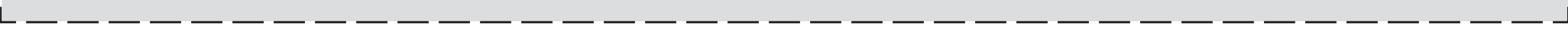

\section{INTRODUCTION}

Medicinal plants are playing a crucial role in the development of traditional medicinal system all over the world. Around 1400 plants are currently being used in varied Ayurvedic medicines preparation. From a ancient time, plants have been used as an important source of new therapeutic drugs and many plant species have been screened for identification of therapeutic substances. Clerodendrum is a huge genus and it contains varied plants. Five hundred and eighty species of this genus have been reported till now and are widely distributed in Asia, Australia, Africa and America [1]. It is native of East India and Malaysia and consists of shrub, small trees and occasionally herbs. Genus clerodendrum was earlier kept in the family verbenaceae but after the phylogenetic study on chloroplast DNA some of the genus of this family including Clerodendrum serratum was shifted to the lamiaceae family and renamed as Rotheca serrata L. [2]. In Chhattisgarh state (India), only two species of this genus have been reported i.e. C. serratum and C. indicum. Both the species shows diverse pharmacological properties and used in Ayurvedic medicine. Clerodendrum serratum $\mathrm{L}$. is one of the threatened species according to Chhattisgarh Medicinal Plant Board.

Clerodendrum serratum is being used in Ayurvedic medicine since ancient time. It's Sanskrit name is Bharangi literally means that which is glorious. In Samhita kala this drug was widely used for many diseases mainly for shwasa (breathlessness), kasa (cough), vrana (wound), shotha (swelling) and many vataja disorders (neurological disorders) [1]. The leaf and root of this plant have much medicinal value. According to the traditional knowledge roots of this plant are the good source of drugs for diseases like asthma, bodyache, bronchitis, cholera, dropsy, eye diseases, inflammations, ophthalmia, rheumatism, malaria, fever, snakebite, tuberculosis, ulcers and wounds [3]. Leaves of Clerodendrum serratum are used to increase appetite and as expectorant. Its leaves, young shoots and flowers are

This is an open access journal, and articles are distributed under the terms of the Attribution 4.0 International (CC BY 4.0) License. This license lets others distribute, remix, tweak, and build upon your work, even commercially, as long as they credit the author for the original creation. You must give appropriate credit, provide a link to the license, and indicate if changes were made. 
used as vegetables. It is one of the few medicinal plants that show antagonistic effect on histamine [4]. Ethanolic extract of the root is accounted for antinociceptive, anti-inflammatory and antipyretic actions [5].

In the present study, a comparative analysis related to chemical profile and antioxidant activity of extracts of $C$. serratum collected from different provinces of Chhattisgarh state of India is carried out, which could be applicable in quality control assessment and therapeutic utility of this plant in the development of natural products.

\section{EXPERIMENTAL}

All the chemicals utilized were of analytical grade and purchased from Hi-Media, S.D. Fine chemicals, Merck, Sigma chemicals and Qualigens.

Collection of plant sample: Clerodendrum serratum L. was collected from three different regions of Chhattisgarh state viz. Jagdalpur, Bilaspur and Raipur cities. Plants were divided into two parts shoot and root. Plant parts were washed twice with running tap water, shade dried and grinded into fine powder by mechanical grinder.

Solvent extraction: Each samples (10 g) were extracted in four different solvents viz. hexane, chloroform, methanol and water by Soxhlet apparatus. Filtrate was evaporated to dryness in an electric oven. The obtained crude extract was packed in air-tight plastic containers and stored in the refrigerator at $-20^{\circ} \mathrm{C}$ for further analysis. The percentage yield of the extract was calculated using the following formula:

$$
\text { Yield }(\%)=\frac{\text { Weight of extract }}{\text { Weight of plant sample }} \times 100
$$

Preliminary phytochemical screening for plant samples: Small amount of all dried crude extracts were used for phytochemical screening of different natural compounds viz. alkaloids, flavonoids, carbohydrate, saponin, terpenoids, steroides, tanin, glycosides and total phenolic as per the reported methods [6-8].

Determination of total phenolic content: All the extracts were subjected for determination of total phenolic content by the following method [9]. In brief, $200 \mu \mathrm{L}$ of extract were mixed with $200 \mu \mathrm{L}$ of two-fold diluted Folin-Ciocalteu reagent, and then incubated for $1 \mathrm{~min}$. After $1 \mathrm{~min}, 600 \mu \mathrm{L}$ of $20 \%$ (w/v) sodium bicarbonate and $5 \mathrm{~mL}$ distilled water was added. Samples were mixed thoroughly and incubated for $1 \mathrm{~h}$ at room temperature. Absorbance was recorded at $760 \mathrm{~nm}$ against methanol as blank and the results are expressed as gallic acid equivalent (mg GAE/g of dry mass).

Determination of flavonoids: Flavonoid contents were determined by using the protocol as described eslewhere [10,11]. Briefly, $0.25 \mathrm{~mL}$ of each extract and rutin standard solution (25$125 \mu \mathrm{g} / \mathrm{mL}$ ) was mixed with $1.25 \mathrm{~mL}$ of distilled water in a test tube, followed by addition of $75 \mu \mathrm{L}$ of a $5 \%$ (w/v) $\mathrm{NaNO}_{2}$ solution. After $6 \mathrm{~min}, 150 \mu \mathrm{L}$ of $10 \%$ (w/v) aluminum chloride solution was added and the mixture was allowed to stand for a further 5 min before $0.5 \mathrm{~mL}$ of $1 \mathrm{M} \mathrm{NaOH}$ was added. The mixture was made up to $2.5 \mathrm{~mL}$ by distilled water and mixed well. The absorbance was measured immediately at $510 \mathrm{~nm}$. The results of samples were expressed as $\mathrm{mg}$ of rutin equivalents (mg Ru/g of dry mass).
Total antioxidant activity: Following method [12] was used to measure the total antioxidant activity of all the extracts. In brief, $0.3 \mathrm{~mL}$ of extract and ascorbic acid standard solution $(15-90 \mu \mathrm{g} / \mathrm{mL})$ was mixed with $3 \mathrm{~mL}$ of reagent solution $(0.6 \mathrm{M}$ sulfuric acid, $28 \mathrm{mM}$ sodium phosphate and $4 \mathrm{mM}$ ammonium molybdate) and incubated in water bath at $95{ }^{\circ} \mathrm{C}$ for $90 \mathrm{~min}$. All the samples were cooled and absorbance was recorded at $695 \mathrm{~nm}$. The antioxidant activity is expressed as the number of gram equivalent of ascorbic acid (mg AS/g of dry mass).

Determination of free radical scavenging activity by DPPH: Free radical scavenging activity was measured according to the reported method [13] with slight modification. In brief, $0.6 \mathrm{~mL}$ of extracts were mixed with $2 \mathrm{~mL}$ of methanolic solution of $0.1 \mathrm{mM} \mathrm{DPPH}$. Then the mixture was shaken thoroughly as well as incubated at room temperature for $30 \mathrm{~min}$ and absorbance was measured at $517 \mathrm{~nm}$ in a spectrophotometer. DPPH scavenging activity of various fractions was calculated as follows:

$$
\text { Inhibition }(\%)=\frac{\mathrm{A}_{\text {control }}-\mathrm{A}_{\text {sample }}}{\mathrm{A}_{\text {control }}} \times 100
$$

Statistical analysis: Data were analyzed using the analytical software SPSS (version 16). Mean difference of all the treatments were compared via one way analysis of variance (ANOVA) and significant difference between the treatments were analyzed using Duncan's multiple range test at $5 \%$ significance level. Data of percentage inhibition was non-parametric so they were first subjected to Arcsine transformation for making the data parametric then analyzed by SPSS.

\section{RESULTS AND DISCUSSION}

The morphological characteristics of any plant is used in the pharmaceutical industry and considered as primary steps to establish their quality control profile. As per the guidelines of World Health Organization (WHO) [14], pharmacognostic standards should be used as a protocol for the identification and authentication of herbal drugs [15-17].

In the present study, the plants were collected from three difference provinces of Chhattisgarh state i.e. Jagdalpur, Bilaspur and Raipur for the comparative study of their phytochemical and secondary metabolite contents. It is observed that size of leaf and inflorescence was higher in plants collected from Jagdalpur and Bilaspur as compared to Raipur possibly due to the humidity and frequent drainage of soil where plant was grown. No any differences were observed in colour, venation and phyllotaxy of leaf for all plants.

To compare the phytochemical contents of different parts (shoot and root) of plants collected from different regions, they were subjected for extraction by hot percolation method by using different solvents (hexane, chloroform, methanol and water). The colour of hexane extract was yellow, chloroform extract was light green, methanol extract was dark green and water extract was dark brown. Extractive value of different extract has been mentioned in Table-1. The data shows that percentage yield is higher in methanol and water extract whereas no significant differences were observed in extractive value of different parts and plants of different regions. 
TABLE-1

EXTRACTIVE VALUE (\%) OF C. serratum L. COLLECTED FROM DIFFERENT PROVINCES OF CHHATTISGARH

\begin{tabular}{|c|c|c|c|c|c|c|c|c|}
\hline \multirow{3}{*}{ Location } & \multicolumn{8}{|c|}{ Yield (\%) } \\
\hline & \multicolumn{2}{|c|}{ Hexane } & \multicolumn{2}{|c|}{ Chloroform } & \multicolumn{2}{|c|}{ Methanol } & \multicolumn{2}{|c|}{ Water } \\
\hline & Shoot & Root & Shoot & Root & Shoot & Root & Shoot & Root \\
\hline Jagdalpur & 18.4 & 16.1 & 21.5 & 20.8 & 26.1 & 25.3 & 28.6 & 27.4 \\
\hline Bilaspur & 17.7 & 17.8 & 19.5 & 20.1 & 24.7 & 25.7 & 29.5 & 27.2 \\
\hline Raipur & 18.0 & 17.0 & 20.9 & 20.0 & 25.8 & 26.0 & 29.1 & 29.0 \\
\hline
\end{tabular}

Results of preliminary phytochemical analysis: A preliminary phytochemical analysis was conducted to identify the main chemical classes present in $C$. serratum L. Results showed that the extract of different regions contain almost same class of phytochemical hence, there is no differences observed in their chemical contents. In general, qualitative differences were not observed, characterized by a higher presence of phenols, flavonoids and alkaloids. However, differences of phytochemical were found in different solvents. Methanolic and water extracts contain all class of phytochemical tested except cardiac glycoside whereas chloroform contain very less group of phytochemical i.e. carbohydrate, phenol, flavonoids and steroids were present.

Total phenolic content: The total phenolic content of all the extracts was determined from linear regression equation of calibration curve $\left[y=0.011 x-0.003\left(R^{2}=0.992\right)\right]$ and expressed as gallic acid equivalent in $\mathrm{mg} / \mathrm{g}$ of dry extract. The results (Table-2) revealed that phenolic content is highest in methanolic extract of shoot collected from Jagdalpur followed by Raipur. According to ANOVA results, the difference in phenolic content of all the samples is statistically significant at $(\mathrm{p} \leq 0.05 ; \mathrm{df}=23,48 ; \mathrm{F}=146.7)$.
Total flavonoid content: Flavonoid contents of all the extracts was determined from linear regression equation of calibration curve $\left[\mathrm{y}=0.000 \mathrm{x}-0.007\left(\mathrm{R}^{2}=0.964\right)\right]$ and expressed as $\mathrm{mg}$ of rutin equivalents ( $\mathrm{mg} \mathrm{Ru} / \mathrm{g}$ of dry extract). The results (Table-2) revealed that flavonoid content is highest in methanolic extract of shoot collected from Jagdalpur. According to ANOVA results, the difference in the flavonoid content of all the samples is statistically significant at ( $\mathrm{p} \leq 0.05$; $\mathrm{df}=$ $23,48 ; \mathrm{F}=334.4)$.

Antioxidant activity: In the present study, ascorbic acid was taken as standard and antioxidant activity was determined from linear regression equation of calibration curve $[y=0.010 x$ $\left.+0.072\left(\mathrm{R}^{2}=0.983\right)\right]$ and expressed as ascorbic acid equivalent in $\mathrm{mg} / \mathrm{g}$ of dry extract. The results (Table-2) revealed that antioxidant activity is maximum in methanolic extract of root and shoot of plant collected from Jagdalpur followed by shoot of Raipur. Statistically significant difference in the antioxidant activity of all samples is revealed by ANOVA $(\mathrm{p}<0.05$; $\mathrm{df}=$ 23,48; F = 210.604).

Free radical scavenging activity by DPPH method: For the determination of free radical scavenging activity of all extracts, DPPH method was followed [13]. Ascorbic acid was

TABLE-2

TOTAL PHENOLIC CONTENT, FLAVONOID CONTENT, TOTAL ANTIOXIDANT ACTIVITY AND FREE RADICAL SCAVENGING ACTIVITY (DPPH) OF DIFFERENT EXTRACT OF C. serratum L. COLLECTED FROM DIFFERENT PROVINCE OF CHHATTISGARH (INDIA)

\begin{tabular}{|c|c|c|c|c|c|c|}
\hline Place & $\begin{array}{c}\text { Plant } \\
\text { materials }\end{array}$ & Solvent & $\begin{array}{l}\text { Total phenolic content } \\
\text { (mg GAE/g of dry mass) }\end{array}$ & $\begin{array}{c}\text { Flavonoid content (mg } \\
\text { Ru/g of dry mass) }\end{array}$ & $\begin{array}{l}\text { Total antioxident activity } \\
\text { (mg AS/g of dry mass) }\end{array}$ & $\begin{array}{c}\text { DPPH } \\
\text { assay }(\%)\end{array}$ \\
\hline \multirow{8}{*}{ Jagdalpur } & \multirow{4}{*}{ Shoot } & Hexane & $1.95 \pm 0.19 \mathrm{hi}$ & $24.37 \pm 3.32 \mathrm{k}$ & $61.80 \pm 5.30 \mathrm{~g}$ & $13.77 \pm 0.36 \mathrm{k}$ \\
\hline & & Chloroform & $3.86 \pm 0.46 \mathrm{~g}$ & $43.72 \pm 1.02 \mathrm{ij}$ & $125.31 \pm 5.96 \mathrm{e}$ & $19.63 \pm 0.25 i$ \\
\hline & & Methanol & $20.0 \pm 1.30 a$ & $333.87 \pm 5.36 a$ & $324.59 \pm 6.28 a$ & $70.07 \pm 0.33 a$ \\
\hline & & Water & $7.18 \pm 0.38 \mathrm{ef}$ & $88.40 \pm 6.90 \mathrm{f}$ & $185.91 \pm 6.69 \mathrm{~d}$ & $50.47 \pm 0.27 \mathrm{e}$ \\
\hline & \multirow{4}{*}{ Root } & Hexane & $1.28 \pm 0.08 \mathrm{i}$ & $21.99 \pm 1.61 \mathrm{k}$ & $54.85 \pm 0.51 \mathrm{gh}$ & $8.97 \pm 0.72 \mathrm{~m}$ \\
\hline & & Chloroform & $3.14 \pm 0.40 \mathrm{gh}$ & $33.50 \pm 0.88 \mathrm{jk}$ & $106.89 \pm 8.90 f$ & $16.23 \pm 0.11 j$ \\
\hline & & Methanol & $15.57 \pm 0.89 b$ & $198.58 \pm 1.66 \mathrm{~d}$ & $276.98 \pm 4.28 \mathrm{a}$ & $64.67 \pm 0.20 b$ \\
\hline & & Water & $7.88 \pm 0.32 \mathrm{e}$ & $141.84 \pm 4.01 \mathrm{e}$ & $184.15 \pm 7.70 \mathrm{~d}$ & $50 \pm 0.33 \mathrm{e}$ \\
\hline \multirow{8}{*}{ Bilaspur } & \multirow{4}{*}{ Shoot } & Hexane & $1.58 \pm 0.08 \mathrm{i}$ & $23.06 \pm 5.45 \mathrm{k}$ & $61.74 \pm 5.24 \mathrm{~g}$ & $8.9 \pm 0.21 \mathrm{~m}$ \\
\hline & & Chloroform & $4.13 \pm 0.20 \mathrm{~g}$ & $54.08 \pm 3.80 \mathrm{hi}$ & $128.68 \pm 5.14 \mathrm{e}$ & $12.53 \pm 0.25 \mathrm{kl}$ \\
\hline & & Methanol & $12.23 \pm 0.76 \mathrm{~d}$ & $281.16 \pm 7.73 b$ & $230.60 \pm 5.94 c$ & $55.8 \pm 0.21 d$ \\
\hline & & Water & $6.11 \pm 0.34 f$ & $64.79 \pm 2.54 \mathrm{gh}$ & $129.02 \pm 0.44 \mathrm{e}$ & $39.73 \pm 0.16 \mathrm{~g}$ \\
\hline & \multirow{4}{*}{ Root } & Hexane & $2.20 \pm 0.13 \mathrm{hi}$ & $38.57 \pm 1.20 \mathrm{ijk}$ & $43.55 \pm 3.34 \mathrm{hi}$ & $4.57 \pm 0.63 \mathrm{o}$ \\
\hline & & Chloroform & $4.32 \pm 0.04 \mathrm{~g}$ & $56.58 \pm 0.88 \mathrm{hi}$ & $103.67 \pm 4.44 f$ & $9.00 \pm 0.58 \mathrm{~m}$ \\
\hline & & Methanol & $11.97 \pm 0.37 d$ & $232.40 \pm 8.70 c$ & $186.84 \pm 7.26 \mathrm{~d}$ & $51.23 \pm 0.22 \mathrm{e}$ \\
\hline & & Water & $7.12 \pm 0.12 \mathrm{ef}$ & $79.72 \pm 0.49 \mathrm{fg}$ & $124.95 \pm 6.43 \mathrm{e}$ & $35.17 \pm 0.16 h$ \\
\hline \multirow{8}{*}{ Raipur } & \multirow{4}{*}{ Shoot } & Hexane & $1.42 \pm 0.26 \mathrm{i}$ & $25.53 \pm 3.32 \mathrm{k}$ & $56.53 \pm 3.37 \mathrm{gh}$ & $11.5 \pm 0.441$ \\
\hline & & Chloroform & $3.89 \pm 0.27 \mathrm{~g}$ & $44.96 \pm 2.26 \mathrm{ij}$ & $134.69 \pm 3.68 \mathrm{e}$ & $16.57 \pm 0.35 j$ \\
\hline & & Methanol & $15.70 \pm 0.31 b$ & $302.30 \pm 17.80 \mathrm{a}$ & $258.47 \pm 5.81 b$ & $61.83 \pm 0.55 c$ \\
\hline & & Water & $6.87 \pm 0.22 \mathrm{ef}$ & $76.11 \pm 7.19 \mathrm{fg}$ & $221.32 \pm 4.50 \mathrm{c}$ & $45.40 \pm 0.35 f$ \\
\hline & \multirow{4}{*}{ Root } & Hexane & $2.10 \pm 0.12 \mathrm{hi}$ & $22.89 \pm 2.98 \mathrm{k}$ & $35.96 \pm 3.52 \mathrm{i}$ & $5.77 \pm 0.75 n$ \\
\hline & & Chloroform & $3.16 \pm 0.03 \mathrm{gh}$ & $48.97 \pm 4.42 \mathrm{hij}$ & $117.12 \pm 6.22 \mathrm{ef}$ & $8.93 \pm 0.69 \mathrm{~m}$ \\
\hline & & Methanol & $14.25 \pm 0.57 \mathrm{c}$ & $286.82 \pm 4.39 \mathrm{ab}$ & $220.37 \pm 6.33 c$ & $50.47 \pm 0.17 \mathrm{e}$ \\
\hline & & Water & $6.54 \pm 0.02 \mathrm{ef}$ & $80.85 \pm 5.37 \mathrm{fg}$ & $191.69 \pm 5.63 d$ & $35.05 \pm 0.35 h$ \\
\hline
\end{tabular}

Each experiment was repeated thrice. Data are represented as Mean \pm SE within a column followed with same alphabets are not significantly different at $\mathrm{p}<0.05$ (DMRT). 

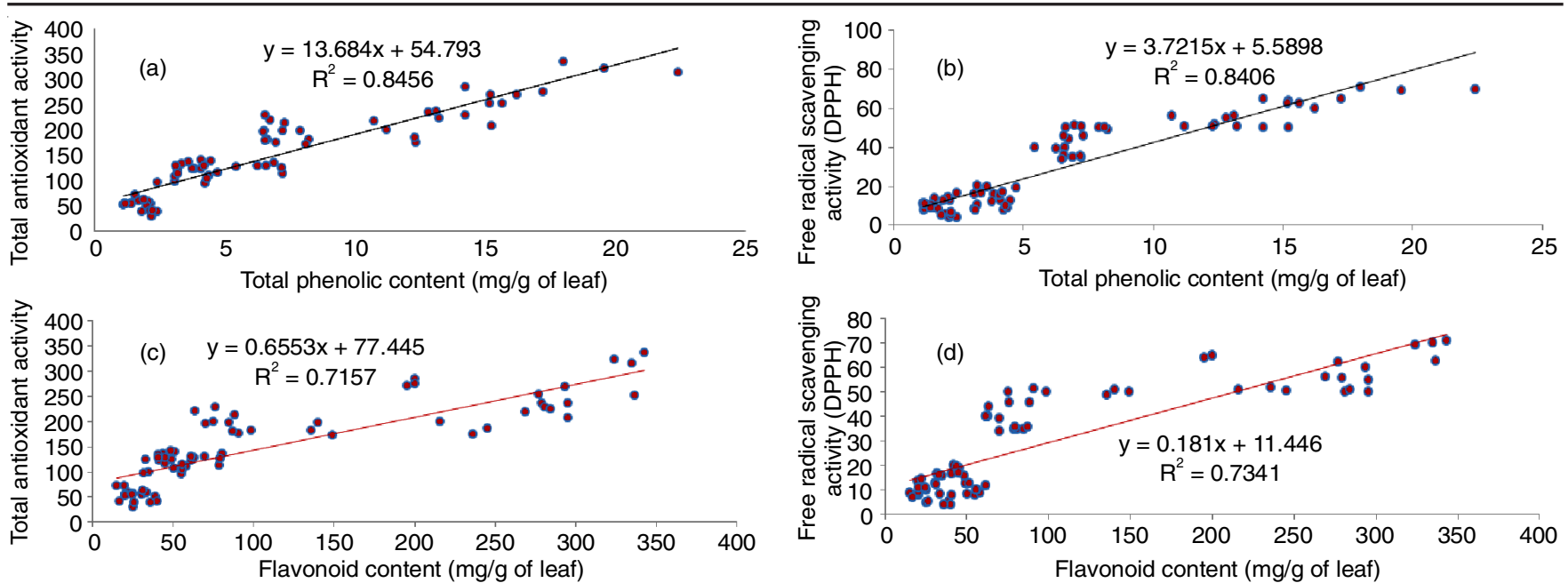

Fig. 1. Correlation between total phenolic content and total antioxidant activity and free radical scavenging activity (DPPH) (a,b); correlation between flavonoid content and total antioxidant activity and free radical scavenging activity (DPPH) (c, d)

used as standard and free radical scavenging activity was determined.

Table-2 revealed that free radical scavenging activity is highest in methanolic extract of shoot collected from Jagdalpur followed by the methanolic extract of root of same plant sample. Statistically significant difference in the free radical scavenging activity of all samples is revealed by ANOVA $(\mathrm{p}<0.05$; $\mathrm{df}=$ 23,48; F = 124.9).

Correlation of phenolic content and flavonoid content with antioxidant activity and free radical scavenging activity: Phenolic compounds are ubiquitous bioactive compounds and a varied group of secondary metabolites generally present in higher plants [18]. These compounds have the capacity to destroy free radicals as they contain hydroxyl groups. They give up hydrogen atoms from their hydroxyl groups to radicals and form stable phenoxyl radicals; hence, playing an important role in antioxidant activity. Flavonoids are also important phyto-chemical commonly present in leaves, flowering tissue and pollens. These phytochemical can modulate lipid peroxidation involved in atherosclerosis, thrombosis and carcinogenesis. Identified properties of flavonoids comprise free radical scaven-ging property, strong antioxidant activity, inhibition of hydrolytic and oxidative enzymes (Phospholipase A2, cyclooxygenase, lipoxygenase) and anti-inflammatory action [19,20]. In the present study, a correlation between antioxidant activity of plant extract and its phenolic and flavonoid content is also observed. Present findings also support the previous reports. A highly significant $(\mathrm{P}<0.01)$ correlation between antioxidant activity and phenolic content $(r=0.91$ and $r=0.92$ for total antioxidant activity and DPPH, respectively) and antioxidant activity and flavonoid content $(\mathrm{r}$ $=0.84$ and $\mathrm{r}=0.86$ for total antioxidant activity and DPPH, respectively) of plant extract was observed (Fig. 1).

\section{Conclusion}

The pharmacognostic study performed for this plant species has established the micromorphologic features of leaves and stems, together with some physico-chemical parameters of plant material and extracts, which are essential for correct identification of plants and contribute to the development of norms for quality control of the species. In addition, its qualitative analysis revealed that it is a good source of medicinally important phytochemical. Finally, antioxidant activity of these extracts could suggest pharmacological use of this plant and contribute to scientific validation of Clerodendrum serratum as an herbal product, which has been used for centuries in ayurvedic medicine. Further research is needed for identification of active compounds present in it.

\section{ACKNOWLEDGEMENTS}

The authors acknowledge their sincere thanks to BSRUGC scheme (Sanction letter no. L/22/SLS/RSU/2014) for providing fund to carryout research work.

\section{CONFLICT OF INTEREST}

The authors declare that there is no conflict of interests regarding the publication of this article.

\section{REFERENCES}

1. N. Shrivastava and T. Patel, Med. Aromat. Plant Sci. Biotechnol., 1, 142 (2007).

2. D.A. Steane, R.W. Scotland, D.J. Mabberley, S.J. Wagstaff, P.A. Reeves and R.G. Olmstead, Syst. Bot., 22, 229 (1997); https://doi.org/10.2307/2419455.

3. K.R. Keshava Murthy, Medicinal Plants of Karnataka, Karnataka Forest Department, Bangalore, India, p. 399 (1994).

4. R.N. Chopra, S.L. Nayar and I.C. Chopra, Glossary of Indian Medicinal Plants, CSIR Publications: New Delhi, India, p. 1956-1992 (1956).

5. N. Narayanan, P. Thirugnanasambantham, S. Viswanathan, V. Vijayasekaran and E. Sukumar, J. Ethnopharmacol., 65, 237 (1999); https://doi.org/10.1016/S0378-8741(98)00176-7.

6. H.O. Edeoga, D.E. Okwu and B.O. Mbaebie, Afr. J. Biotechnol., 4, 685 (2005);

https://doi.org/10.5897/AJB2005.000-3127.

7. S.K. Agrawal, K.C. Samanta and R.C. Chipa, Int. J. Pharm. Life Sci., 1, 99 (2010).

8. C. Niratker Prity and M. Singh, Int. J. Appl. Biol. Pharm. Technol., 5, 131 (2014).

9. K. Slinkard and V.L. Singleton, Am. J. Enol. Vitic., 28, 49 (1977).

10. S. Sakanaka, Y. Tachibana and Y. Okada, Food Chem., 89, 569 (2005); https://doi.org/10.1016/j.foodchem.2004.03.013.

11. R.A. Khan, Chem. Cent. J., 6, 126 (2012); https://doi.org/10.1186/1752-153X-6-126. 
12. P. Prieto, M. Pineda and M. Aguilar, Anal. Biochem., 269, 337 (1999); https://doi.org/10.1006/abio.1999.4019.

13. M.P. Prasad, S. Sushant and B.K. Chikkaswamy, Int. J. Mol. Biol., 3, 71 (2012); https://doi.org/10.9735/0976-0482.3.3.71-76.

14. World Health Organization (WHO), Quality Control Methods for Medicinal Plant Materials, World Health Organization, Geneva: Switzerland (1998).

15. D.D. Pramanick, J. Pharmacogn. Phytochem., 5, 120 (2016).

16. Y. Zhu, L. Zhao, X. Wang and P. Li, J. Pharm. Pharmacogn. Res., 4, 95 (2016).
17. Y.I. Gutiérrez, R. Scull, L. Monzote, K.M. Rodríguez, A. Bello and W.N. Setzer, Plants, 7, 110 (2018); https://doi.org/10.3390/plants7040110.

18. K. Robards, P.D. Prenzler, G. Tucker, P. Swatsitang and W. Glover, Food Chem., 66, 401 (1999); https://doi.org/10.1016/S0308-8146(99)00093-X.

19. E. Frankel, Nutritional benefits of flavonoids. International Conference of Food Factors: Chemistry and Cancer Prevention, Hamamastu, Japan, Article ID C6-2 (1995).

20. J. Zhishen, T. Mengcheng and W. Jianming, Food Chem., 64, 555 (1999); https://doi.org/10.1016/S0308-8146(98)00102-2. 